\title{
Printed Antenna Design and Simulation for 5G using HFSS
}

\author{
Mahvish', Tanika² \\ ${ }^{1}$ M.Tech Scholar, ${ }^{2}$ Assistant Professor \\ ${ }^{1}$ Department of Electronics and Communication Engineering, \\ 1,2Swami Vivekananda Institute of Engineering and Technology, Ramnagar, Banur, Punjab, India
}

\begin{abstract}
How to cite this paper: Mahvish | Tanika "Printed Antenna Design and Simulation for 5G using HFSS" Published in International Journal of Trend in Scientific Research and Development (ijtsrd), ISSN: 24566470, Volume-3 | Issue-4, June 2019, pp.961-965, URL: https://www.ijtsrd.c om/papers/ijtsrd24 011.pdf

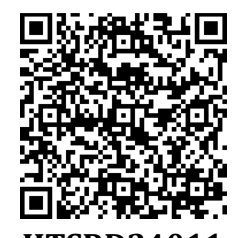
IITSRD24011
\end{abstract}

Copyright (c) 2019 by author(s) and International Journal of Trend in Scientific Research and Development Journal. This is an Open Access article distributed under the terms of the Creative Commons

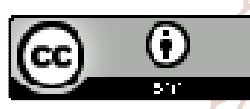
Attribution License (CC BY 4.0) (http://creativecommons.org/licenses/ by $/ 4.0$ )
ABSTRACT

With expanding number of users, the demand for better technology also increases. The fifth Generation 5G technology would be one of the best technologies to meet the need of increased capacity demand, massive connectivity better speed by using the large amount of spectrum in the millimeter wave band, with $5 \mathrm{G}$ it is expected to get $80-100 \mathrm{Mbps}$ speed. The need for $5 \mathrm{G}$ technology, methodology designing of antenna and various simulations is offered. The micro strip patch antenna is used here in $5 \mathrm{G}$ technology is relatively inexpensive to manufacture and design because of its simple physical geometry. Micro strip Patch Antenna shows multi-band characteristics and has a compact structure and hence has emerged as a promising candidate for handheld devices the proposed idea is implemented by using HFSS software which is used for antenna designing.

\section{Keywords: $4 G, 5 G, U H D, I P, G S M$}

\section{Introduction}

The early communication systems supported only analogy voice and now provide wide range of different applications to large number of users. First origination mobile system supported voice only. Within previous minor years, we have seen continuous development of mobile telecommunications by the birth of $2 \mathrm{G}$ bands, $3 \mathrm{G}$ and $4 \mathrm{G}$ bands wireless networks respectively. Digital networking procedures as if modulation techniques, Frequency reuse, Packet switching and physical layer simulation etc. have appeared in this change. With the expanding appeal of smart devices, nowadays IP based networks has grown into an essential Resultant, new multimedia applications for mobile users. Open Market is overwhelm with these applications and has opened up new deals for mobile user and service providers. The forthcoming of mobile communications is likely to be very distinct to that which we are used to today. While interest for portable broadband will drastically increase day by day, largely consumed by UHD video and better screens, we are already seeing the developing impact of the human capabilities of technology as the stuff around us become ever more linked. The approaching 5 th generation network is certain to output a constant Gbps data speed experience across a wide range of user scenarios. $5 \mathrm{G}$ is more just a new wireless transmission technology called radio technology. It is a gate opener to new communication capabilities and used cases, many of that are still unknown to us. For the bandwidth aspects, here millimeter wave mobile communications approach is developed and a micro-strip receiver has implemented for the $5 \mathrm{G}$ cellular network/device. Respecting the $4 \mathrm{G}$ and $5 \mathrm{G}$ network bands, its focus is approaching smooth combination of cellular networks such as GSM and 3G, WLAN and Bluetooth. Micro-strip patch receiver (MPAs) has beautiful and boundless features due to its low profile, small size, and lightweight, low cost as well as to the fact these are very simple to construct, suited to planer and nonlaner surfaces. However, their future use in definite systems is finite of their almost narrow bandwidth. For generating the excessive-frequency mm-wave electric signals, the usage of traditional electronics turns into less financially appealing; consequently, there is an excessive concern to at once generate $\mathrm{mm}$-wave alerts within the optical domain. For that reason in these paintings, the photonic technology, variation and circulation of $60 \mathrm{GHz}$ thickness band signals to be applied in 5G that have been recommended and established already. Basically, a photonics founded totally mm-wave is a laser beam together with two or extra coherent longitudinal modes with frequency spacing same to the wanted mm-wave. As the longitudinal method beat with each dissimilar in the photodiode, the definite electrical mmwave can be achieved.

\section{Problem Definition}

The fundamental intention of this thesis is to style a microstrip patch antenna for milli meter wave mobile communication at $38 \mathrm{GHz}$ frequency by exploitation the fundamental micro-strip conductor methodology and line calculation analyze from HFSS computer code. In projected style excited in its basic mode contains a most radial asymmetry within the direction perpendicular to the patch (broadside) and is $8.4316 \mathrm{db}$. during this style, input reflection coefficients or the S11 parameter for the antenna is -42 decibel at resonant frequency a pair of. $8 \mathrm{GHz}$. the height Gain 8.211 decibel and therefore the most $-10 \mathrm{~dB}$ information measure of $0.0565 \mathrm{GHz}$ are achieved in simulation of S11 parameter for center frequency a pair of.8 $\mathrm{GHz}$. Another vital parameter of AN antenna is that the 
International Journal of Trend in Scientific Research and Development (IJTSRD) @ www.ijtsrd.com eISSN: 2456-6470

information measure it covers. Most of the time solely resistance or come loss information measure is given. However, it's vital to comprehend that many different definitions of information measure exist: radial asymmetry Bandwidth, polarization information measure and potency bandwidth. radial asymmetry and potency are usually combined to achieve information measure

\section{Methodology}

\section{Results}

The results obtained after using the HFSS software. The HFSS is an efficient platform for designing micro strip Patch Antenna.

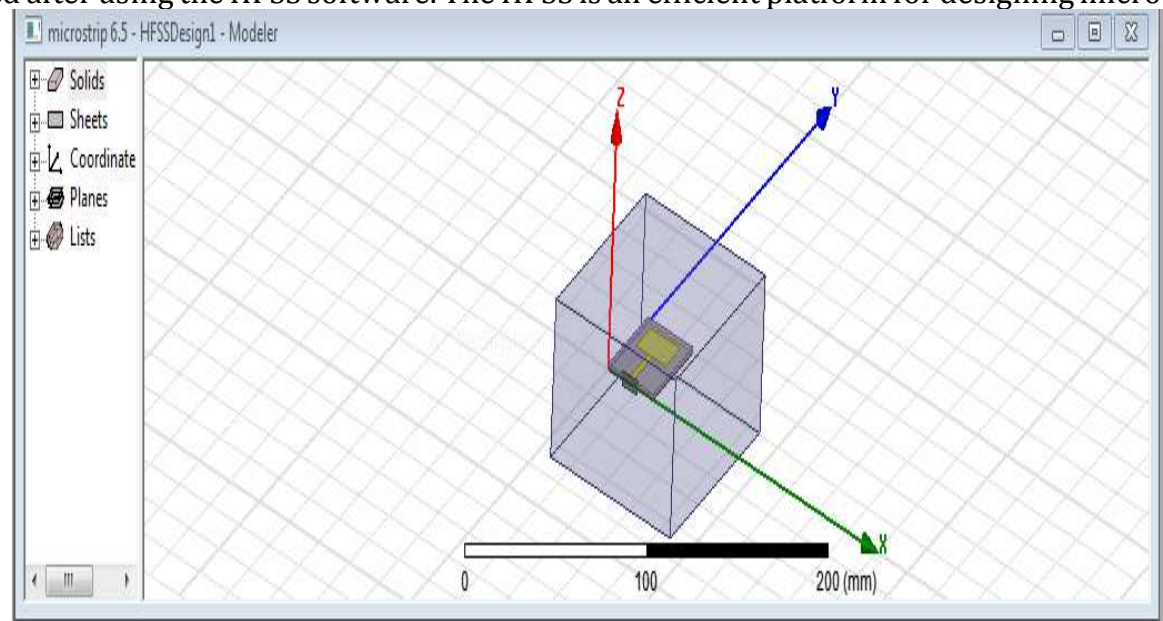

Designed micro strip Patch Antenna using HFSS.

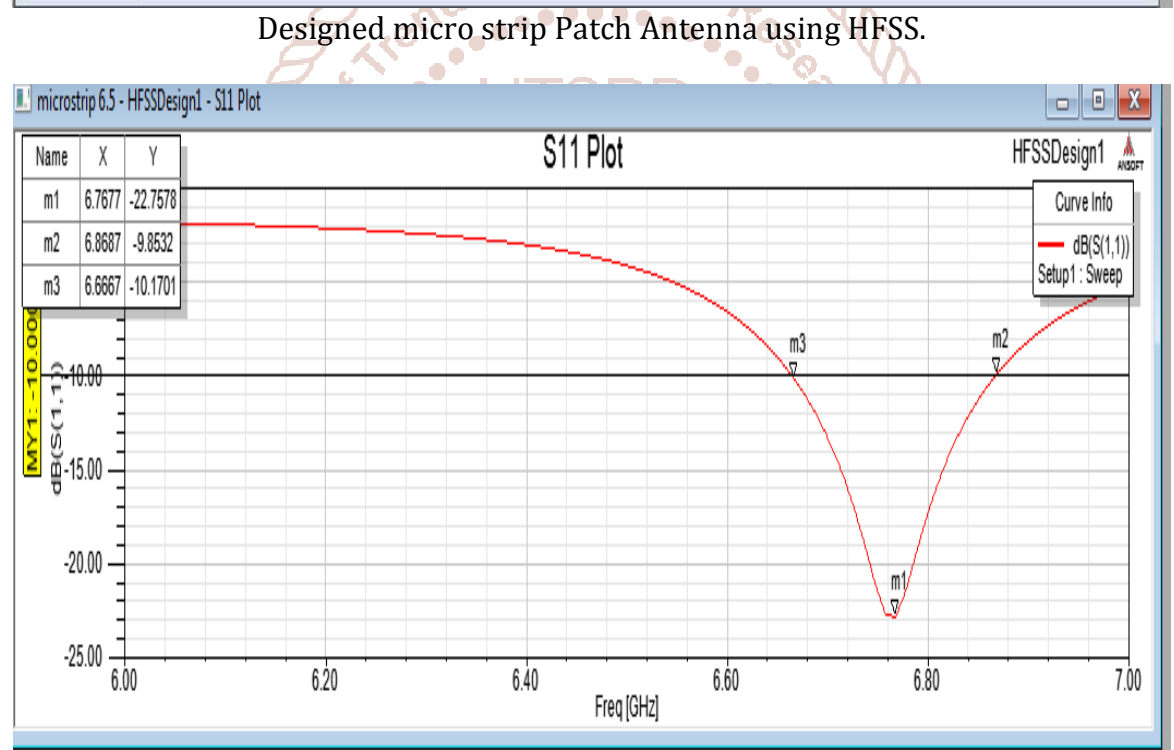

Return Loss Plot

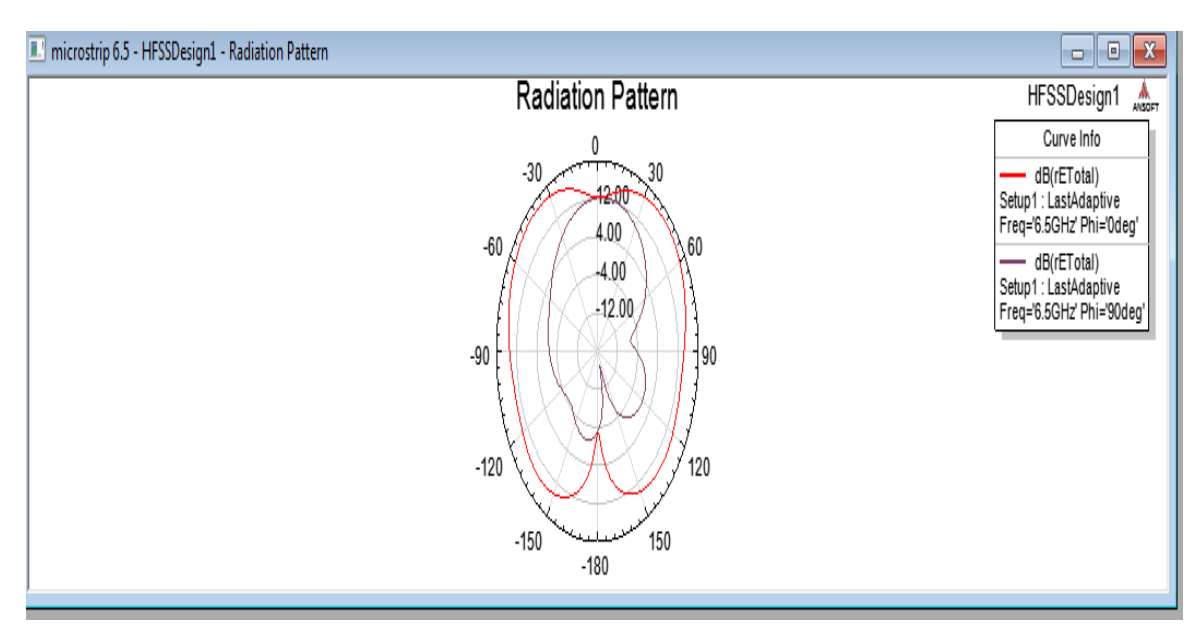

Radiation Pattern
The methodology involves the use of theoretical analysis and the system simulation. For the simulation approach, the event simulator HFSS package tool needs to be used to investigate the number of parameters. The HFSS software (o design a Micro-strip Patch Antenna and the parameters investigated are Return Loss, Radiation Pattern, The Gain, VSWR, Impedance, Directivity etc.
Return Loss Plot

Radiation Pattern 
International Journal of Trend in Scientific Research and Development (IJTSRD) @ www.ijtsrd.com eISSN: 2456-6470
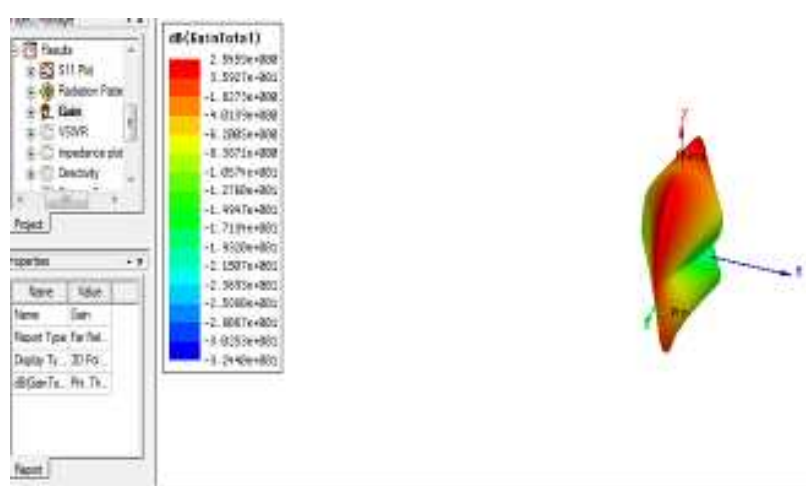

The Gain Plot

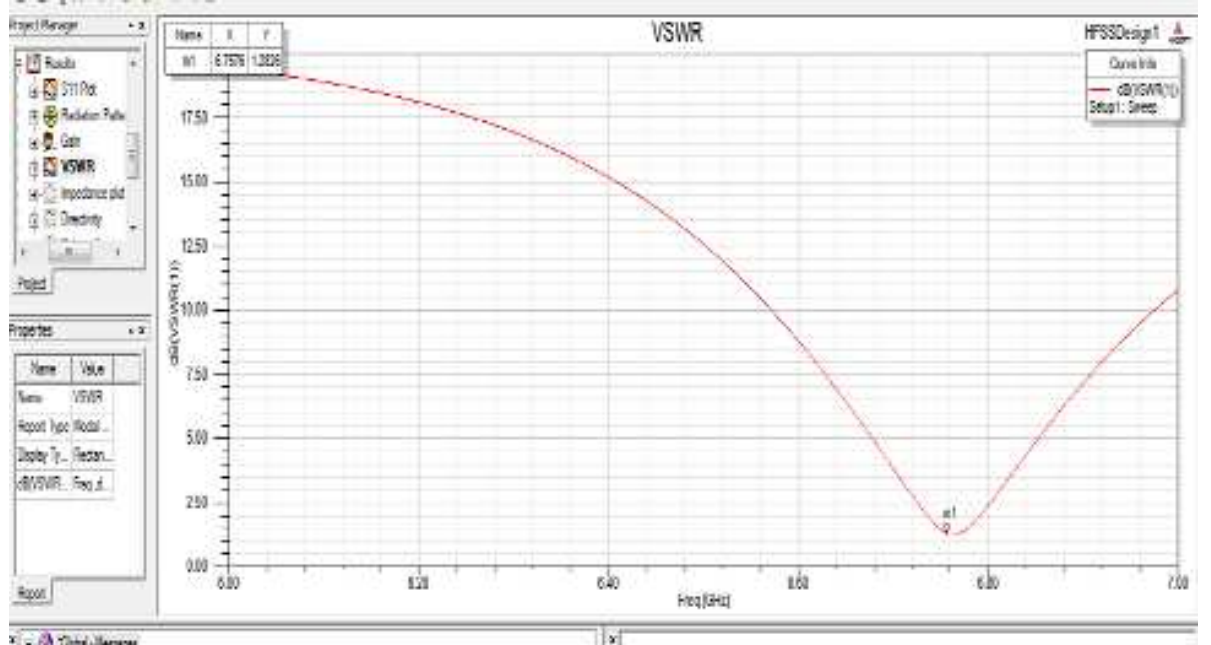

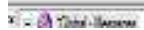
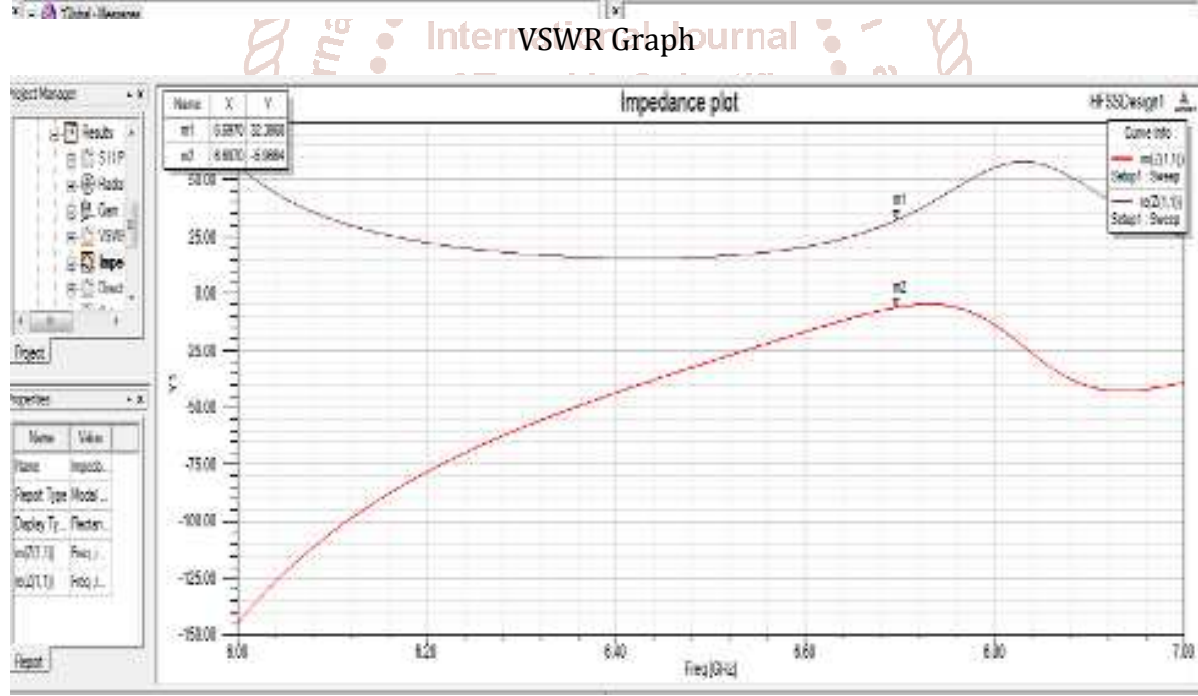

Impedance Plot
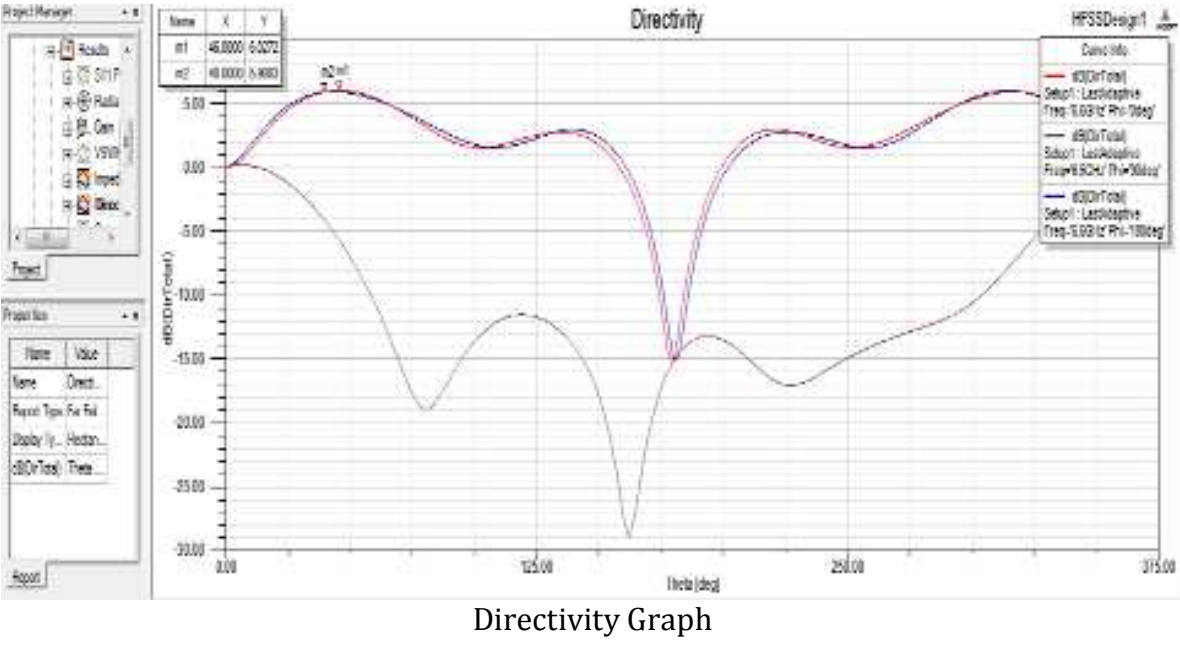

@ IJTSRD | Unique Paper ID - IJTSRD24011 | Volume-3 | Issue - 4 | May-Jun 2019 
International Journal of Trend in Scientific Research and Development (IJTSRD) @ www.ijtsrd.com eISSN: 2456-6470

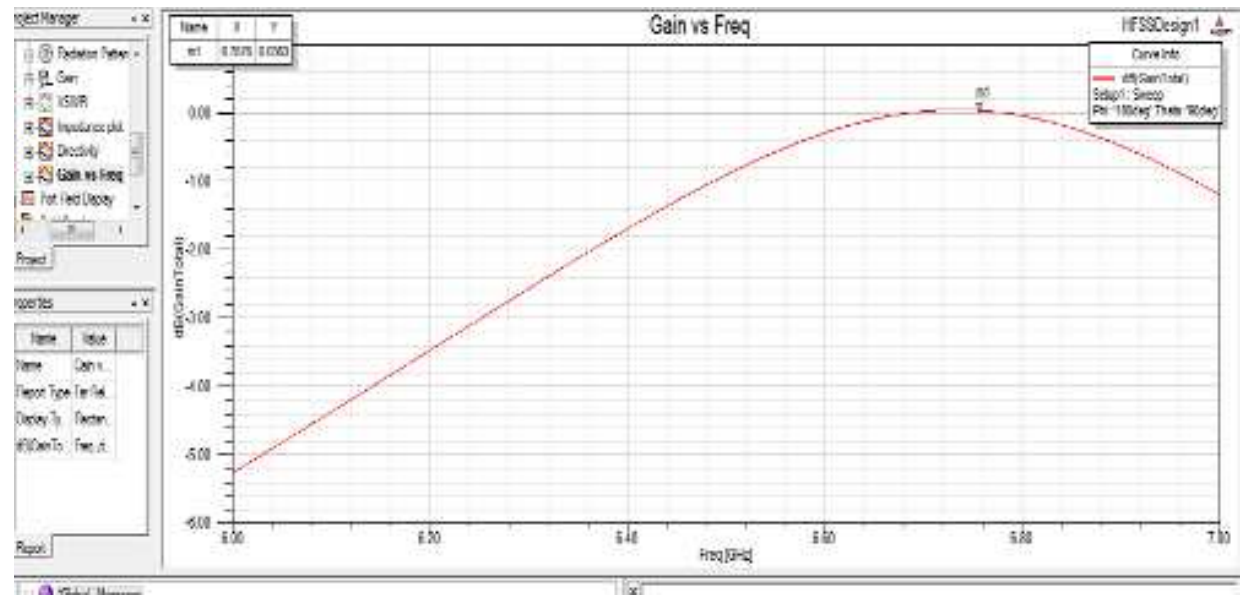

Gain vs. Frequency Graph

Results
\begin{tabular}{|c|c|}
\hline PARAMETERS & VALUES \\
\hline Return Loss & $-23 \mathrm{db}$ \\
\hline Resonance Frequency & $6.76 \mathrm{GHz}$ \\
\hline Bandwidth & $200 \mathrm{MHz}$ \\
\hline Highest Radiation Intensity & $2.63 \mathrm{db}$ \\
\hline Directivity & $5.87 \mathrm{db}$ \\
\hline VSWR & $1.28 \mathrm{db}$ \\
\hline
\end{tabular}

Comparison between my base paper and my work

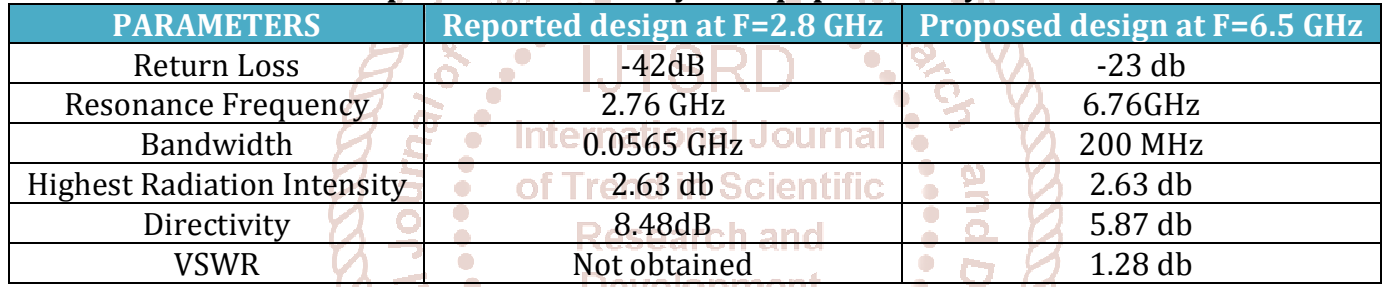

\section{Conclusion:}

The paper explains the micro-strip patch antenna fundamentals and HFSS software. The paper explains in details the steps needed to develop a complete simulation of micro-strip patch antenna using the popular HFSS software. The results are given with parameter values and the comparison between parameters of bases paper and our proposed work.

\section{References}

[1]. BrajlataChauhan, Sandip Vijay, S. C. Gupta, "MillimetreWave Mobile Communications Micro strip Antenna for 5G - A Future Antenna", International Journal of Computer Applications Volume 99- No.19, August 2014.

[2]. Theodore S. Rappaport, Shu Sun, RimmaMayzus, Hang Zhao, YanivAzar, "Millimetre Wave Mobile Communications for 5G Cellular", IEEE Access. Vol. 1, 2013.

[3]. M. Samimi, K. Wang, Y. Azar, G. N. Wong, R. Mayzus, H. Zhao, J. K. Schulz, S. Sun, F. Gutierrez, and T.S. Rapp port, " $28 \mathrm{GHz}$ angle of arrival and angle of departure analysis for outdoor cellular communications using steerable-beam antennas in New York City" , in Proc. IEEE Veh. Technol. Conf., Jun. 2013.

[4]. M. Cudak, A. Ghosh, T. Kovarik, R. Ratasuk, T. Thomas, F. Vook, and P. Moorut, "Moving towards mmwave- based beyond-4G (B-4G) Technology", in Proc. IEEE Veh. Technol. Soc. Conf., 2013.

[5]. Singh, Sapana, Pratap Singh, "Key Concepts and Network Architecture for 5G Mobile Technology.", International Journal of Scientific Research Engineering \& Technology,1.5,2012.

[6]. H. Zhao, R. Mayzus, S. Sun, M. Samimi, J. K. Schulz, Y. Azar, K. Wang, G. N. Wong, F. Gutierrez, Jr., and S. T. Rapp port, " $28 \mathrm{GHz}$ millimetre wave cellular communication measurements for reflection and penetration loss in and around buildings in New York City", in Proc. IEEE Int. Conf. Comm., Jun. 2013.

[7]. N. Murdock, E. Ben-Dor, Y. Qiao, J. I. Tamir, and T. S. Rapp port „,,A $38 \mathrm{GHz}$ cellular outage study for an urban campus environment"', in Proc. IEEE Wireless Commun. Netw. Conf., Apr. 2012.

[8]. S. Rajagopal, S. Abu-Surra, Z. Pi, and F. Khan, “'Antenna array design formulti-Gbpsmmwave mobile broadband communication", in Proc. IEEE Global Telecommun. Conf., Dec. 2011.

[9]. G. Nair, "Single-feed Dual-frequency Dual-polarized Slotted Square micro strip Antenna", Microw. Opt. Technol. Lett., 25, pp. 395-397, June 20, 2000.

[10]. W.F. Richards, Y.T. Lo, and D.D. Harrison, "An Improved Theory Formicro strip Antennas and Applications", IEEETrans. antennas Propagat.29, pp. 38-46, Jan. 1981. 
International Journal of Trend in Scientific Research and Development (IJTSRD) @ www.ijtsrd.com eISSN: 2456-6470

[11]. W.F. William F. Richards, "micro strip Antennas", in Antenna Handbook, Y. T. Lo and S.W. Lee, Eds. NewYork: Van Nostrand Reinhold, 1993.

[12]. L. Alatan, M. I. Aksun, K. Leblebicioglu, and M. T. Birand,"Useof Computationally Efficient Method of Moments in the Optimization of Printed Antennas", IEEE Trans. Antennas Propagate., 47, pp. 725-732, Apr. 1999.

[13]. D. H. Shaubert, F. G. Garrar, A. Sindoris, and S. T. Hayes, "microstripantennas with Frequency Agility and Polarization Diversity", IEEE Trans. Antennas Propagate.,29, pp. 118-123, Jan. 1981.

[14]. W. F. Richards and Y. T. Lo, "Theoretical and Experimental Investigation of a micro strip Radiator with Multiple Lumped Linear Loads", Electromagn, 3(34), pp. 371-385,July-Dec. 1983.

[15]. S. C. Pan and K.L. Wand, "Dual Frequency Triangular micro strip Antenna with Shorting Pin", IEEE Trans. Antennas Propagate, 45, pp. 1889-1891, Dec. 1997.

[16]. Ms. Varsharani Mokal1, Prof S. R.Gagare2, Dr. R. P. Labade "Analysis of Micro strip patch Antenna Using Coaxial feed and Micro strip line feed for Wireless Application" ,IOSR Journal of Electronics and Communication Engineering (IOSR-JECE) Volume 12, Issue 3, Ver. III (May - June 2017), PP 36-41 www.iosrjournals.org

[17]. Deal W., N. Kaneda, J. Sor, Y. Qian, and T. Itoh, “A New Quasiyagi Antenna for Planar Active Antenna Arrays", IEEE.

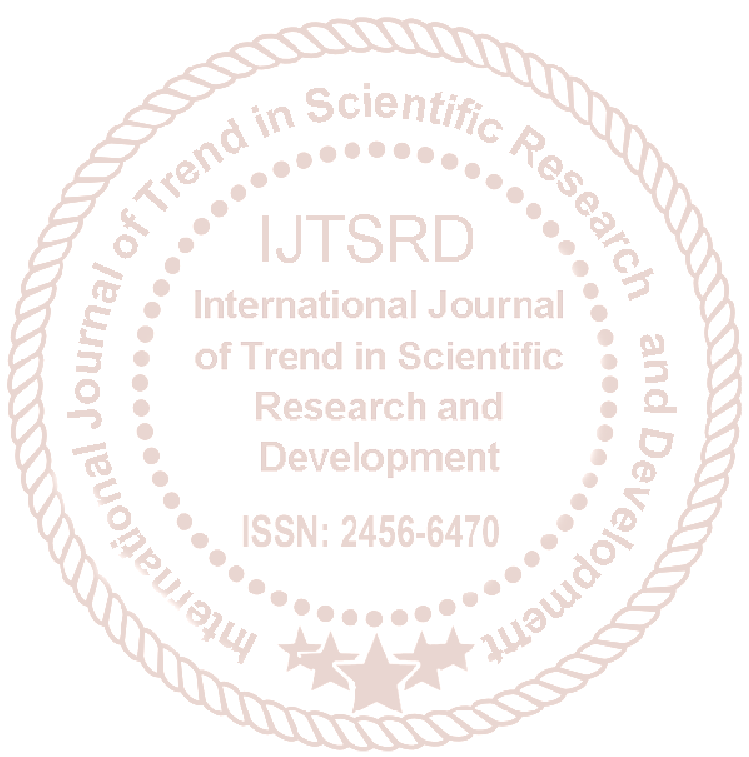

